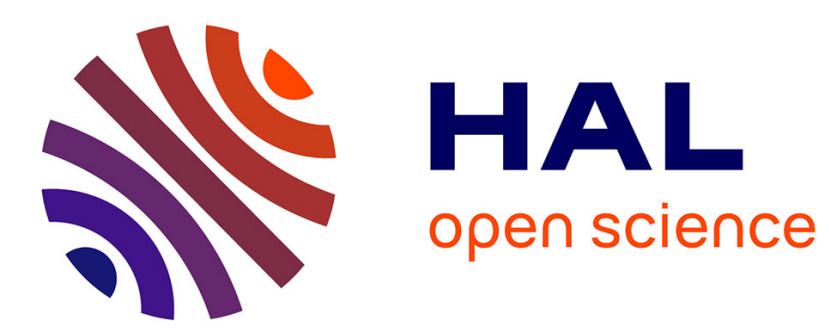

\title{
A comparative analysis of interface erosion tests
}

Pierre-Louis Regazzoni, Didier Marot

\section{To cite this version:}

Pierre-Louis Regazzoni, Didier Marot. A comparative analysis of interface erosion tests. Natural Hazards, 2013, 67 (2), pp.937-950. 10.1007/s11069-013-0620-3 . hal-01004679

\section{HAL Id: hal-01004679 \\ https://hal.science/hal-01004679}

Submitted on 9 Mar 2018

HAL is a multi-disciplinary open access archive for the deposit and dissemination of scientific research documents, whether they are published or not. The documents may come from teaching and research institutions in France or abroad, or from public or private research centers.
L'archive ouverte pluridisciplinaire HAL, est destinée au dépôt et à la diffusion de documents scientifiques de niveau recherche, publiés ou non, émanant des établissements d'enseignement et de recherche français ou étrangers, des laboratoires publics ou privés. 


\title{
A comparative analysis of interface erosion tests
}

\author{
Pierre-Louis Regazzoni · Didier Marot
}

\begin{abstract}
Interface erosion is one of the main phenomena in dams, dikes and their foundations which may increase their failure risk. In laboratories, the jet erosion test (JET) and the hole erosion test (HET) are commonly used for the evaluation of the sensibility of interface erosion of fine soils. The results are interpreted by two distinct methods that are valid for one test only. A new energy analysis of the tests is developed, relating the total eroded mass to the dissipated fluid energy, and a new erosion resistance index is proposed. Seven naturally occurring fine-grained soils, covering a large range of erodibility, are compacted with the Proctor protocol, and they are tested with the two devices. It was shown that by using the commonly used methods, the values of the erosion coefficient are systematically higher with the JET than with the HET and the HET critical shear stress is about fifty times higher than the JET critical shear stress. Thus, the relative soil classifications yielded by the two erodimeters are not exactly the same. Based on energy analysis, values of erosion resistance index are roughly the same for each tested soil with the two apparatuses and a single classification of soil erodibility is obtained.
\end{abstract}

Keywords Dams - Embankment - Interface erosion - Hole erosion test . Jet erosion test $\cdot$ Energy

\section{Introduction}

Erosion is a widely present issue in civil and environmental engineering, especially for the safety of dams and dikes. The history of failures of such structures by erosion associated with flow through a dam, its foundation or over its top makes it paramount that we develop means to model these erosion processes; doing so requires associated methods for

P.-L. Regazzoni

Egis Géotechnique, 3 rue Dr. Schweitzer, 38180 Seyssins, France

D. Marot

Institut de Recherche en Génie Civil et Mécanique, Université de Nantes, 58 rue Michel Ange, BP 420, 44606 Saint-Nazaire Cedex, France

e-mail: didier.marot@univ-nantes.fr 
quantifying the erodibility of embankment and foundation materials. Two types of erosion can be distinguished: internal erosion and interface erosion. Internal erosion takes place inside the soil matrix, whereas interface erosion occurs at an interface between two types of soil or at the surface between soil and water. This surface is relatively large compared with the grain scale.

Several testing devices for characterizing the sensibility of surface erosion of finegrained soils were proposed by various researchers. These tests apply hydraulic loading to a soil sample by a variety of methods. Among these testing devices, the hole erosion test (HET) and the jet erosion test (JET) are the most commonly used. The HET was used by Wan and Fell (2004) in a constant-head configuration to characterize the erodibility of a variety of soils. The JET was developed by Dunn (1959) and had been further improved by Hanson and Cook (2004). With this device, Hanson et al. (1990) performed numerous studies exploring many aspects of soil erodibility.

The existing interpretative methods for both apparatuses are based on a linear erosion law which relates the mass rate of erosion, $\dot{m}$, or the volumetric rate of erosion, $\dot{\varepsilon}$, to the excess hydraulic shear stress $\tau$ above a threshold value $\tau_{c}$. This threshold of hydraulic shear stress represents the minimal value needed to initiate erosion. In equation form, the erosion laws are:

$$
\begin{gathered}
\dot{m}=k_{d, m}\left(\tau-\tau_{C}\right) \\
\dot{\varepsilon}=k_{d}\left(\tau-\tau_{C}\right)
\end{gathered}
$$

with $k_{d, m}$ and $k_{d}$ : erosion rate coefficients, with $k_{d, m}=k_{d} \rho_{D}$ where $\rho_{D}$ is soil dry density.

The erodibility of a particular soil can be characterized by the erosion rate coefficient and the critical shear stress determined from one of the aforementioned test methods. Although both tests characterize soil erodibility in terms of similar parameters, Wan and Fell (2004) and Hanson and Simon (2001) have each proposed specific classification systems for describing soil erodibility.

This paper describes a new method of interpretation based on energy approach for both apparatuses. An experimental comparison of these two devices across a variety of soil types is undertaken. Soil erodibility characterizations through existing methods and through new energy method are compared. An erosion resistance index is proposed and leads to a single classification of soil erodibility.

\section{Presentation of devices and interpretation by existing methods}

The principle of HET and the data analysis techniques are described in Wan and Fell (2004). A constant head is applied to produce flow through a pre-drilled hole in a soil sample, which was compacted in a standard Proctor mould (see Fig. 1). When erosion is produced, the resulting increase in the diameter $(\phi)$ over time is estimated by monitoring the related increase in flow rate.

The hydraulic shear stress in a circular pipe with a diameter $\phi$ and a length $L$ can be computed as:

$$
\tau=\frac{\Delta H \rho g}{L} \frac{\phi}{4}
$$

where $\Delta H$ : differential head losses were measured between upstream and downstream thanks to a differential pressure transducer; $\rho$ : fluid density; and $g$ : gravity. 


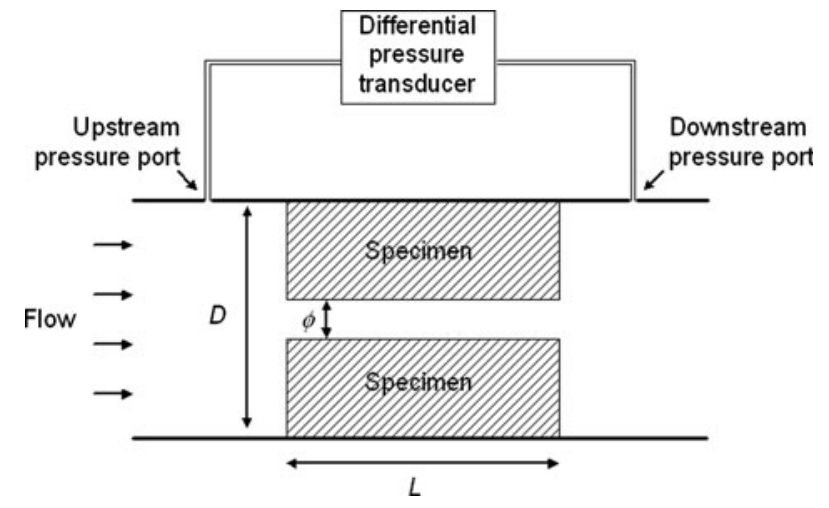

Fig. 1 Schematic representation of the hole erosion test cell

Wan and Fell (2004) related the shear stress to a friction coefficient and the fluid velocity, depending on whether the flow is "turbulent linear with the square of water speed" or "laminar linear with the water speed." At the start and the end of the test, flow and diameter measurements allow determining the friction coefficient values. The instantaneous value of friction coefficient during the test is then computed by a linear interpolation with time between the initial and final values. Finally, it is possible to compute a diameter and to deduce the rate of erosion at each time. A linear correlation between the computed shear stresses and erosion rates during the progressive erosion period allows obtaining $k_{d}$ and $\tau_{C}$.

In the case of a turbulent flow, Bonelli and Brivois (2008) proposed a scaling law. Assuming the friction coefficient and the specimen length to be constant and defining dimensionless diameters and flow rates based upon reference values at time zero, it is possible to express the dimensionless diameter as a parametric function of the dimensionless flow rate:

$$
\left(\frac{Q(t)}{Q(0)}\right)^{2}=\left(\frac{\phi(t)}{\phi(0)}\right)^{5}
$$

By integrating the erosion law including the expression of shear stress, an analytical solution for the evolution of the dimensionless diameter is expressed by:

with

$$
\frac{\phi(t)}{\phi(0)}=\left(\exp \left(\frac{t}{t_{\mathrm{er}}}\right)-1\right)\left(1-\frac{\tau_{C}}{\tau(0)}\right)+1
$$

$$
t_{\mathrm{er}}=\frac{2 L}{\rho g \Delta H k_{d}}
$$

and $\tau(0)$ : initial shear stress for the system at $t=0$.

By a least-squares method, the measured dimensionless flow rates can be fitted to the values predicted by the model to determine values of $\tau_{c}$ and $k_{d}$.

Wan and Fell (2004) proposed classifying the risk of rapid internal erosion failures of embankment dams based on the value of the erosion rate index defined by:

$$
I_{\mathrm{HET}}=-\log _{10}\left(k_{d, m}\right)
$$

A large value of $I_{\mathrm{HET}}$ indicates a slow rate of erosion. It should be emphasized that this index does not depend on the critical shear stress. Six groups of soils are proposed, varying from extremely slow to extremely rapid. 
Wahl et al. (2008) show good agreement between the $I_{\text {HET }}$ values computed by the Wan and Fell method and the Bonelli and Brivois method.

Hanson and Cook (2004) developed the JET. This apparatus is designed to apply a submerged water jet on the face of a soil sample; an apparatus is described in the A.S.T.M. Standard D5852. At increasing time intervals, a point gage passing through the tube measures the depth of scour $(J)$ beneath the nozzle ( $d_{0}$ diameter). The procedures for specimen preparation and compaction are the same as for HET, except that no hole is drilled through the sample. At $t=0$, the initial distance to the interface is written as $J_{0}$. At an infinite time, $J$ tends to a limit, the equilibrium depth $J_{e}$. For distances smaller than $J_{p}=6.2 d_{0}$, the flow consists of a potential core in which the velocity is equal to the initial velocity $u(0,0)$ at the jet origin, and an outer zone, the axial velocity varies inversely with the distance:

$$
u(0, J)=\frac{J_{p}}{J} u(0,0)
$$

The equivalent hydraulic shear stress applied to the soil surface can be computed in function of the water velocity $u(0, J)$ on the centreline of the jet:

$$
\tau=C_{f} \rho u(0, J)^{2}
$$

where $C_{f}$ : friction coefficient, and according to Hanson and Cook (2004), it is assumed to be constant, $C_{f}=0.00416$.

The erosion law is no-dimensionalized and a characteristic time is defined. By integrating the no dimensional erosion law, time is expressed as a function of no dimensional depth $J^{*}$.

$$
t=T_{R}\left(-J^{*}\left|J_{i}^{*}+\frac{1}{2} \operatorname{Ln}\left(\frac{1+J^{*}}{1-J^{*}}\right)\right|_{J_{i}^{*}}^{J^{*}}\right)
$$

with

$$
T_{R}=\frac{J_{e}}{k_{d} \tau_{C}}
$$

and

$$
J^{*}=\frac{J}{J_{e}}
$$

The evolution of the scour depth with time is fitted to a hyperbolic function that predicts the ultimate depth of scour, equivalent to the equilibrium depth (Blaisdell and Anderson 1981). It leads to the determination of the critical shear stress $\tau_{C}$. The experimental data are fitted to the model represented by Eq. (12). This yields an estimate of the characteristic time and the resulting detachment rate coefficient, $k_{d}$, which is expressed on a volumetric basis. For comparison with the HET, one may convert $k_{d}$ to $k_{d, m}$ using $k_{d, m}=k_{d} \rho_{D}$, and the corresponding rate index, named $I_{\mathrm{JET}}$, can be computed from Eq. (7).

The soil erodibility classification proposed by Hanson and Simon (2001) is based on both the critical shear stress and the erosion rate coefficient determined from JETs. The Hanson and Simon system recognizes five categories from very resistant to very erodible materials.

\section{Interpretation by energy method}

\subsection{Principle of energy analysis}

The new analysis proposed here is based on a fluid energy dissipation model and on the measurement of the eroded mass. A volume $V$ of fluid with a mass $M$ is assumed with a 
surface $S$ in contact with environment. The external surface of the volume is oriented by its normal vector from fluid to environment: $\vec{n}$. The energy equation for the fluid between the entrance and the exit of the system can be written by the following equation (White 1999; Regazzoni 2009):

$$
\begin{gathered}
\frac{\mathrm{d} E}{\mathrm{~d} t}=\frac{\mathrm{d}}{\mathrm{d} t} \iiint_{\text {Mass }}\left(e_{\mathrm{int}}+\frac{w^{2}}{2}+\vec{g} \vec{z}\right) \mathrm{d} M=\frac{\partial}{\partial t} \iiint_{\text {Volume }}\left(e_{\text {int }}+\frac{w^{2}}{2}+\vec{g} \vec{z}\right) \rho_{w} \\
\mathrm{~d} V+\oiint_{S}\left(e_{\mathrm{int}}+\frac{w^{2}}{2}+\vec{g} \vec{z}\right) \rho_{w}(\vec{U} \vec{n}) \mathrm{d} S \\
\frac{\mathrm{d} E}{\mathrm{~d} t}=\frac{\mathrm{d} E_{\text {Ther }}}{\mathrm{d} t}+\frac{\mathrm{d} W}{\mathrm{~d} t}
\end{gathered}
$$

and

with $E_{\text {Ther }}$ : energy exchange between the system and the environment; $W$ : mechanical work between the entrance and the exit of the system; $e_{\text {int }}$ : internal energy of the fluid; $\rho_{w}$ : fluid density; $U$ : velocity of the fluid, components $(u, v, w)$; gravity; $z$ : coordinates.

Four assumptions can be used to simplify the equation. The whole experimental system is placed in a temperature-controlled laboratory, and it is supplied with the public water system. Thus, for test duration, the temperature (isothermal in time) and the internal energy $\left(e_{\text {int }}\right)$ are assumed to be constant on the volume. All tests are performed under the same experimental conditions, so the comparison of tests leads to neglect the relative variations of energy exchange between the system and the environment. In consequence, the term $\frac{\mathrm{d} E_{\text {Ther }}}{\mathrm{d} t}$ is negligible. As test results are analysed in steady state (the water speed evolves slowly during a time step), the unsteady term of the kinetic energy can be neglected. Finally, Eq. (13) becomes:

$$
\frac{\mathrm{d} W}{\mathrm{~d} t}=\frac{\partial}{\partial t} \iiint_{\text {Volume }}(\vec{g} \vec{z}) \rho_{w} \mathrm{~d} V+\oiint_{S}\left(\frac{u^{2}}{2}+\vec{g} \vec{z}\right) \rho_{w}(\vec{U} \vec{n}) \mathrm{d} S
$$

\subsection{Energy analysis of HET}

The energy equation is applied between the upstream section $\mathrm{A}$ and the downstream section B. The apparatus is horizontal, so the term $\vec{g} \cdot \vec{z}$ is null on average and Eq. (15) becomes:

$$
\frac{\mathrm{d} W}{\mathrm{~d} t}=\oiint_{S}\left(\frac{u^{2}}{2}\right) \rho(\vec{U} \vec{n}) \mathrm{d} S
$$

The fluid passes successively through a contraction ( $D$ diameter), a hole ( $\phi$ diameter, $L$ length) and finally an expansion ( $D$ diameter) (see Fig. 1$)$.

The hole length appears as short in comparison with the total hydraulic length of the device. Thus, the balance of the energy in the system must take into account the energy dissipation in the contraction and expansion, which will be named the energy dissipation on the singularities. The total energy dissipation is the sum of energy dissipation by the pressure, by viscous work at the control surface and by the singularities. The viscous work is assumed to cause erosion in the hole, and it is assumed to be neglected on the other parts of the system. So the dissipation of total energy in the system can be written as: 


$$
\frac{\mathrm{d} W}{\mathrm{~d} t}=\left.\frac{\mathrm{d} W}{\mathrm{~d} t}\right|_{\text {Erosion }}+\left.\frac{\mathrm{d} W}{\mathrm{~d} t}\right|_{\text {Pressure }}+\left.\frac{\mathrm{d} W}{\mathrm{~d} t}\right|_{\text {Singularities }}
$$

Equations (16) and (17) lead to:

$$
\left.\frac{\mathrm{d} W}{\mathrm{~d} t}\right|_{\text {Erosion }}+\left.\frac{\mathrm{d} W}{\mathrm{~d} t}\right|_{\text {Singularities }}=\oiint_{S}\left(\frac{P}{\rho}+\frac{u^{2}}{2}\right) \rho(\vec{U} \vec{n}) \mathrm{d} S
$$

The sections A and B and the specimen section are identical. Thus, the mass conservation with a same diameter on the whole length lets us assume the same average speed in the section A and in the section B. So Eq. (18) becomes:

$$
\left.\frac{\mathrm{d} W}{\mathrm{~d} t}\right|_{\text {Erosion }}+\left.\frac{\mathrm{d} W}{\mathrm{~d} t}\right|_{\text {Singularities }}=\left(P_{\mathrm{A}}-P_{\mathrm{B}}\right) Q
$$

With the objective of the evaluation of head losses in singularities, a test is performed in the HET with a no erodible polyacrylic model of the specimen with its pre-drilled hole. The total head losses and the flow rate are measured.

The total head loss is the summation of head loss along the hole and of head losses due to the singularities. The contraction/expansion head losses can be computed by a "Borda" formula and experimental coefficients (Idel'Cik and Meury 1986).

$$
\begin{gathered}
\text { Contraction: } \left.\Delta H_{\text {Cont }}=\frac{0.5}{2 g} \quad 1-\left(\frac{\phi}{D}\right)^{2}\right)\left(\frac{4 Q}{\pi \phi^{2}}\right)^{2} \\
\text { Expansion: } \left.\Delta H_{\text {Exp }}=\frac{1}{2 g} 1-\left(\frac{\phi}{D}\right)^{2}\right)^{2}\left(\frac{4 Q}{\pi \phi^{2}}\right)^{2}( \pm 15 \%)
\end{gathered}
$$

Another method consists in estimating the friction head losses in the pipe by using a Colebrook estimation based on interpolation of experimental data. For a turbulent flow (Reynolds number: $\operatorname{Re}=\frac{\rho \bar{U} \phi}{\mu}>2,000, \mu$ : fluid dynamic viscosity), the friction head loss can be expressed by (White 1999):

$$
\begin{gathered}
\Delta H_{\text {friction }}=\lambda \frac{L}{\phi} \frac{\bar{U}^{2}}{2 g} \\
\text { with } \frac{1}{\sqrt{\lambda}}=-2 \log _{10}\left(\frac{\varepsilon / \phi}{3.7}+\frac{2.51}{\operatorname{Re} \sqrt{\lambda}}\right)
\end{gathered}
$$

$\varepsilon$ : rugosity of the pipe, average size of the roughness; in the case of a plastic surface, the rugosity is $0.0015 \mathrm{~mm} \pm 60 \%$ (American Society of Mechanical Engineers quoted by White 1999); $\lambda$ : friction coefficient of the surface.

Thus, the head losses on the singularities can be calculated by the difference of total head losses and friction head losses.

Figure 2 shows the measurements of total head losses versus flow rate. It also shows the difference between total head losses and friction head losses calculated by Eq. (22). This difference represents the singularities' head losses.

These singularities' head losses are well correlated with the sum of the contraction and expansion head losses computed by Eqs. 20 and 21.

If an average value is computed on a range of flow rates from $0.02 \mathrm{l} / \mathrm{s}$ to $0.42 \mathrm{l} / \mathrm{s}$ (corresponding to the HET range), the percentage of head losses transformed into friction and erosion is roughly $25 \%$. 
- Measured total head losses

* Singularities head losses : deduced from friction coefficient

- Singularities head losses : computed with "Borda"
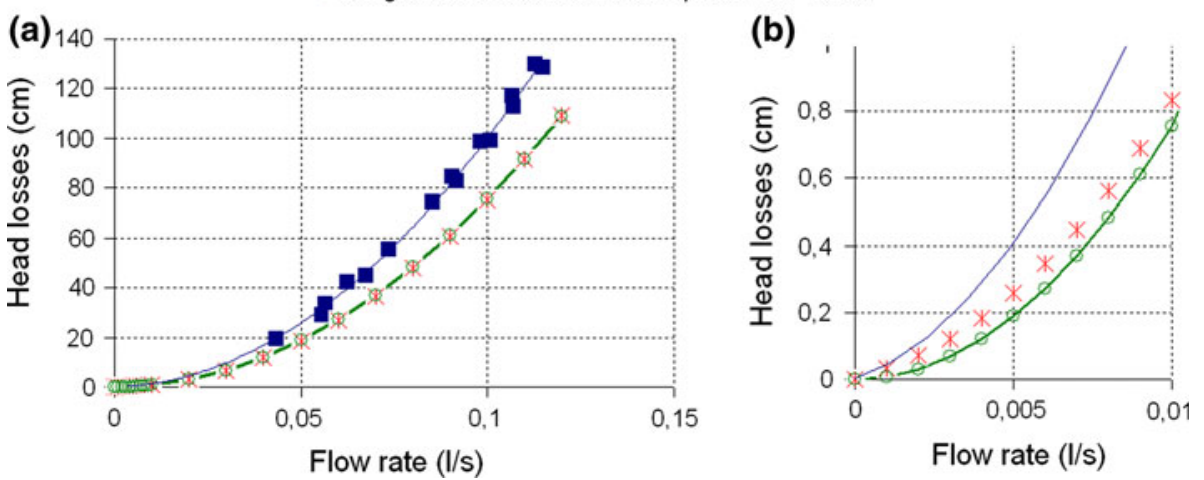

Fig. 2 Head losses for a polyacrylic HET sample versus a high flow rate and b low flow rate

Thus, the temporal derivative of the mechanical work by erosion in a HET can be estimated by:

$$
\left.\frac{\mathrm{d} W}{\mathrm{~d} t}\right|_{\text {Erosion }}=0.25\left(P_{\mathrm{A}}-P_{\mathrm{B}}\right) Q
$$

For convenience, the temporal derivative mechanical work by erosion is named erosion power $\left(P_{\text {erosion }}\right)$.

\subsection{Energy analysis of JET}

In the case of JET, the energy equation (Eq. 15) is applied between the nozzle and the exit of submergence tank. The assumptions of a steady flow in time lead to neglect the term: $\frac{\partial}{\partial t} \iiint_{\text {Volume }}(\vec{g} \vec{z}) \rho \mathrm{d} V$.

In comparison with free jet, jet in front of a soil-water interface is subjected to a deviation from the centreline. It is assumed that the erosion is mainly associated with this deviation, which induces an increase in shear stress and a great variation of pressure. Beltaos and Rajaratnam (1974) conducted tests of impinging circular turbulent jet, and they proposed an expression of the vertical velocity on the jet axis at $J$ depth beneath the nozzle, in function of lateral distance $r$ from centreline of the jet by:

$$
u(r, J)=\exp \left(-0.693\left(\frac{r}{b_{u}}\right)^{2}\right) u(0, J)
$$

with $b_{u}$ : distance from centreline corresponding to a decrease in half vertical velocity $\left(u\left(b_{u}, J\right)=0.5 u(0, J)\right) ; b_{u}=0.093\left(J-J_{p}\right) ; J_{P}$ depth corresponding to the potential core; $u(0, J)$ : vertical velocity at the centre of the jet.

Beltaos and Rajaratnam (1974) observed that wall shear stress increases linearly with lateral distance from jet centreline up to a maximum value obtained for $r=0.14 \mathrm{~J}$ and then decreases with any further increase in $r$. Moreover, when $r / J$ ratio increases from 0 to 0.14 , wall pressure decreases rapidly reaching $10 \%$ of maximum value of stagnation pressure on jet centreline axis. Thus, at $J$ depth, erosion is assumed to appear in space defined by lateral distance from jet centreline $r \leq 0.14 \mathrm{~J}$. 
With the objective to take into account the variation in vertical velocity with the $J$ altitude and the distance $r$ from the jet axe considered, Eqs. 15 and 25 are combined to express the erosion power by:

$$
P_{\text {erosion }}=2 \pi \int_{0}^{0.14} \frac{u^{2}}{2} \rho(\vec{U} \vec{n}) r \mathrm{~d} r=\pi \rho u(0, J)^{3} \int_{0}^{0.14 J}\left[\exp \left(-0.693\left(\frac{r}{b_{u}}\right)^{2}\right)\right]^{3} r \mathrm{~d} r
$$

For $J<J_{P}, u(0, J)=u(0,0)$, with $u(0,0)$ : initial velocity at the jet origin. For $J>J_{P}$, $u(0, J)$ is determined by Eq. (8).

\section{Erodibility of seven soils}

\subsection{Tested soils and preparation}

Thanks to previous HET investigations (Regazzoni 2009), seven soils were selected, covering a large range of erodibility. Table 1 summarizes the soils used in the laboratory tests, their classification and properties.

Soils were prepared for JET and HET testing using methods described in the Bureau of Reclamation Earth Manual (1990), for a total number of 19 tests with each device. The initial water content is measured, and additional water is added to target the optimum water content less one per cent $\left(w_{\text {opt }}-1 \%\right)$. The soil is manually mixed, and the prepared soil is stocked in a plastic bag for at least $36 \mathrm{~h}$. The preparation is compacted according standard Proctor procedure, and the water content is determined on the uncompacted material (an oven is used with $T=105^{\circ} \mathrm{C}$ ). Following compaction, the sample is kept for $12 \mathrm{~h}$ in a plastic bag in a controlled-humidity room $(75 \%)$ before testing.

Two additional experimental precautions were systematically taken. For HET, all specimens were drilled with a same drill, and a rifle-type brush was passed through the hole

Table 1 Classification and properties of soils tested

\begin{tabular}{|c|c|c|c|c|c|c|c|}
\hline \multirow{2}{*}{$\begin{array}{l}\text { Soil } \\
\text { reference } \\
\text { in paper }\end{array}$} & \multirow{2}{*}{$\begin{array}{l}\text { USCS } \\
\text { classification }\end{array}$} & \multicolumn{2}{|c|}{ Atterberg limits } & \multicolumn{2}{|c|}{ Proctor state ( 25 blows) } & \multirow{2}{*}{$\begin{array}{l}\text { Fines } \\
\text { content }^{\mathrm{a}} \\
(\%)\end{array}$} & \multirow{2}{*}{$\begin{array}{l}\text { Clay } \\
\text { content } \\
(\%)\end{array}$} \\
\hline & & $\begin{array}{l}\text { Liquid } \\
\text { limit } \\
(\%)\end{array}$ & $\begin{array}{l}\text { Plasticity } \\
\text { index (\%) }\end{array}$ & $\begin{array}{l}\text { Optimum dry } \\
\text { density }(\mathrm{kg} / \\
\left.\mathrm{m}^{3}\right)\end{array}$ & $\begin{array}{l}\text { Optimum water } \\
\text { content W opt } \\
(\%)\end{array}$ & & \\
\hline TE & CL-ML & 29 & 4 & 1,703 & 16 & 88 & 11 \\
\hline MF & CL & 47 & 34 & 1,815 & 14 & 75 & 33 \\
\hline TF & $\mathrm{CH}$ & 55 & 40 & 1,708 & 17 & 99 & 40 \\
\hline MP & $\mathrm{CH}-\mathrm{CL}$ & 54 & 31 & 1,679 & 17 & 92 & 40 \\
\hline $\mathrm{L}$ & ML & \multicolumn{2}{|c|}{ Nonplastic } & 1,670 & 19 & 99 & 7 \\
\hline M0 & $\mathrm{CL}$ & 44 & 23 & 1,619 & 21 & 98 & 40 \\
\hline M1 & $\mathrm{CL}$ & 34 & 11 & 1,650 & 20 & 98 & 21 \\
\hline
\end{tabular}

USCS United States Customary System

${ }^{\mathrm{a}}$ Fines content $=$ mass fraction in percentage of soil particles finer than $0.075 \mathrm{~mm}$

${ }^{\mathrm{b}}$ Clay content $=$ mass fraction in percentage of soil particles finer than $0.002 \mathrm{~mm}$ 
in downward direction in order to minimize the influence of initial conditions on results. For JET, the initial distance of nozzle from the soil was adjusted so that $J>J_{P}$.

\subsection{Results of analysis by existing methods}

Hanson and Cook's analysis and Bonelli and Brivois' scaling law were used to analyse JET and HET, respectively. The values of the erosion coefficient are systematically higher with the JET than with the HET, and the corresponding mean rate index is systematically smaller with the JET $\left(I_{\mathrm{JET}}\right)$ than with the HET $\left(I_{\mathrm{HET}}\right)$ (see Fig. 3a).

The $I_{\mathrm{JET}} / I_{\mathrm{HET}}$ ratio varies from 0.32 (specimen number 2 of $\mathrm{L}$ soil) to 0.84 (specimen 1 of MF soil). A linear correlation of erosion rate index determined with JET in function of erosion rate index determined with HET can be expressed by:

$$
I_{\mathrm{JET}}=0.655 \quad I_{\mathrm{HET}}+0.004
$$

with: correlation coefficient $R^{2}=0.69$, number of individual test $N=19$.

On average, the HET critical shear stress is about fifty times higher than the JET critical shear stress (Fig. 3b). Moreover, the linear correlation between critical shear stress
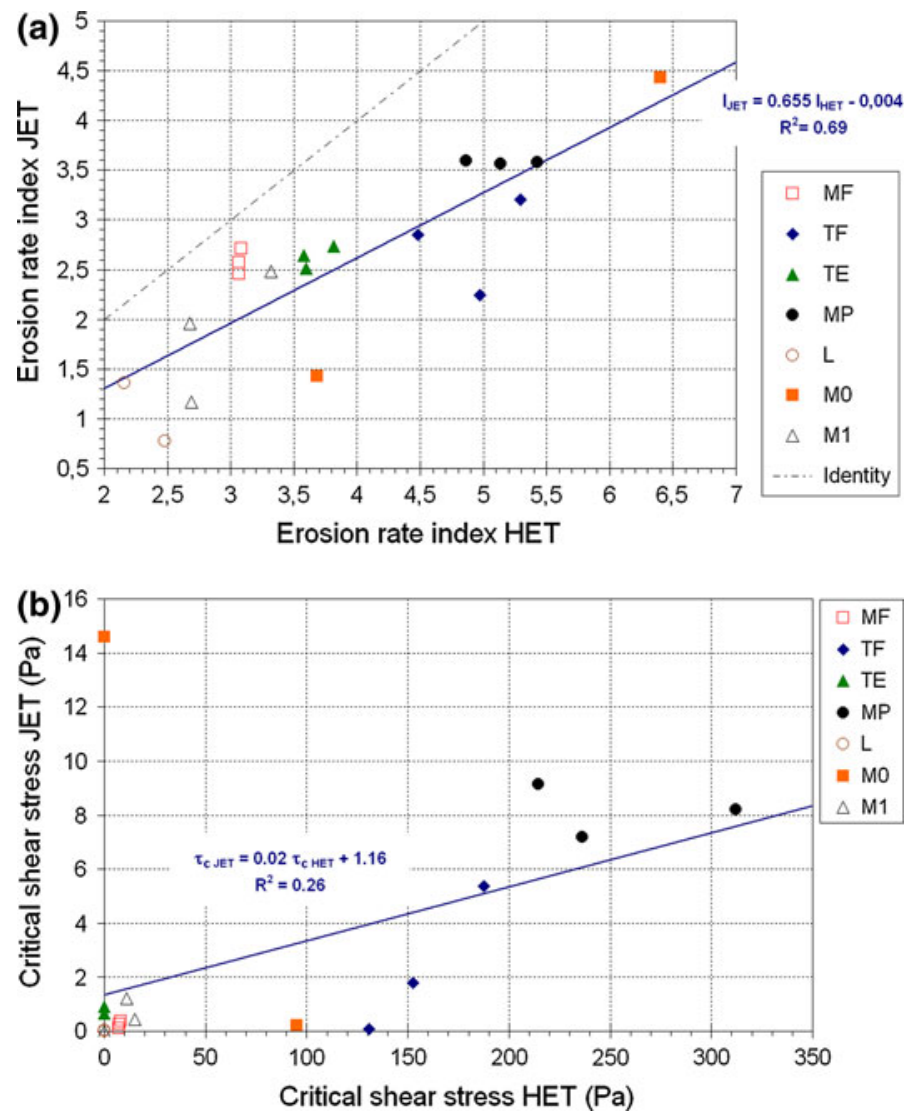

Fig. 3 Values measured with the JET versus values measured with the HET. a Rate index; b critical shear stress 
determined with the two devices [Eq. (28)] is characterized by a very low value of correlation coefficient:

$$
\tau_{c \mathrm{JET}}=0.02 \tau_{c \mathrm{HET}}+1.16 \quad\left(R^{2}=0.26 ; N=19\right)
$$

The HET results and Wan and Fell (2004) description of erosion rate lead us to characterize $\mathrm{L}$ soil as having a rapid erosion development and M1 soil as having rapid to moderately rapid erosion rates. Two soils (MF, TE) have moderately rapid erosion rates while two other soils (MP, TF) exhibit moderately slow to slow erosion development. For M0 soil, the water content of the two tested specimens was 19 and $23 \%$. This water content discrepancy of $4 \%$ between specimens seems to be sufficient to induce a difference of erosion development from moderately rapid to extremely slow, respectively. This difference on erosion sensibility shows the great influence of water content on one hand and that the study of real structure needs to take into account the soil heterogeneities on the other hand.

With the JET results and Hanson and Simon (2001) classification, L soil is classified moderately resistant to erodible. MF and M1 soils are moderately resistant. TF and M0 are moderately resistant to resistant. MP and TE appear resistant.

As showed by Fig. 3a, the relative classification of the erodibility yielded by both apparatuses is not exactly the same. If we consider the erosion rate index determined by JET, nearly identical values are obtained for MF, TE and TF, whereas if we consider the erosion rate index determined by HET, a clear difference appears. MF is the most erodible soil, followed by TE, and TF is the least erodible soil.

In the case of the JET, the friction coefficient has been assumed constant and equal to 0.00416 , that is, equivalent to a friction coefficient defined by Moody $f_{\text {Moody }}=0.0338$. For the HET, the coefficient defined by Moody is computed as the $8 f / \rho$ ratio, with $f$ : friction coefficient. The obtained Moody friction coefficient is in the expected range (Nikuradse, Moody), quoted by White (1999) at the beginning of most tests, but generally it is outside of the range by a factor 10 or 100 at the end of most tests. For example, during test TF-1, Reynolds number ranges from 16,000 to 18,000 . The relative roughness can be expressed by the ratio of the mean diameter of grain and the specimen hole diameter. The value of relative roughness is 0.0006 at the beginning of test and 0.0001 at the end. According to the Moody chart, the corresponding friction coefficient is about 0.027 . From HET analysis, the computed Moody friction coefficient increases from 0.048 to 2.16. This may explain the difference in the critical shear stress computed by the JET and the HET. In addition, in the case of the HET, rate of erosion and hydraulic shear stress are deduced from the flow rate measurement. Erosion process is an interaction between soil and water, and thus, independent measurements for water and soil may characterize more precisely this process compared with an approach based solely on a one-phase measurement.

\subsection{Results of analysis by energy method}

For the HET and JET, the erosion power is computed according to Eqs. (24) and (26), respectively. The rate of erosion is defined as the ratio of increment of eroded dry mass to corresponding increment of time test duration. Figure $4 \mathrm{a}$ shows the rate of erosion in function of the erosion power which is determined by HET.

For seven specimens (TE-3, MP-1, MP-2, MP-3, TF-1, TF-2, TF-3), erosion rate remains inferior to $4.10^{-4} \mathrm{~kg} \mathrm{~s}^{-1}$ while erosion power increases up to $1.25 \mathrm{~W}$. For the other specimens, rate of erosion can reach $3.5 \cdot 10^{-3} \mathrm{~kg} \mathrm{~s}^{-1}$ for an erosion power inferior to $0.3 \mathrm{~W}$ (see Fig. 4). For all specimens, erosion rate increases linearly with erosion power. 
Figure 5 shows erosion rate in function of erosion power measured by JET. In the same range of erosion rate $\left(0-3.5 \cdot 10^{-3} \mathrm{~kg} \mathrm{~s}^{-1}\right)$, the erosion power stays inferior to $0.3 \mathrm{~W}$ (excepted M0-2: $P_{\text {erosion }}=1.25 \mathrm{~W}$ ). For JET, erosion power stays relatively constant and the erosion rate increases sharply during the first minutes of the test and afterwards it slowly decreases.

The comparison of the erosion power for both tests underlines that evolution during the time of hydraulic loading is different, which induces a distinct variation in erosion rate.

With the objective to take into account the history of hydraulic loading, the energy dissipated by erosion $\left(E_{\text {erosion }}\right)$ is determined by the time integration of instantaneous erosion power. Thus, for each test, the erosion energy is computed for the test duration by trapezoidal rule. Eroded dry mass $\left(m_{\mathrm{dry}}\right)$ is computed by eroded wet mass/ $\left(1+w_{\mathrm{i}}\right)$ ratio, with $w_{\mathrm{i}}$ : initial water content when specimen was compacted. Figure $6 \mathrm{a}, \mathrm{b}$ shows the cumulative eroded dry mass in function of erosion energy for HET and JET, respectively.

For HET, the range of erosion energy $0-4,300 \mathrm{~J}$ is associated with an eroded dry mass up to $1.21 \mathrm{~kg}$ (excepted M0-2: $E_{\text {erosion }}=15,168 \mathrm{~J}, m_{\text {dry }}=0.036 \mathrm{~kg}$ ). For JET, the maximum of erosion energy is $1,077 \mathrm{~J}$ and the eroded dry mass is inferior to $1.6 \mathrm{~kg}$ (excepted M0-2: $E_{\text {erosion }}=23,729 \mathrm{~J}, m_{\mathrm{dry}}=0.1437 \mathrm{~kg}$ ).

The erosion resistance index is built with the erosion energy and the cumulative eroded dry mass:
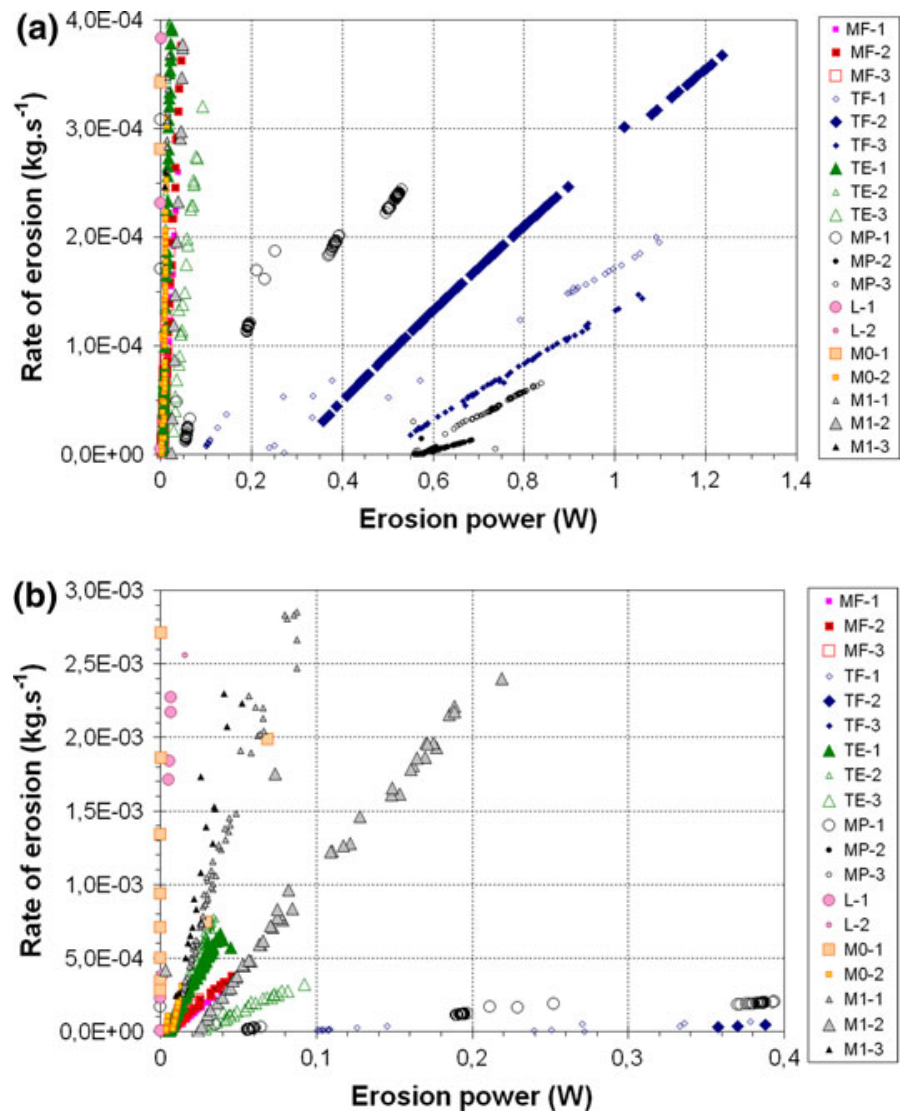

Fig. 4 Rate of erosion determined by HET versus a high erosion power and $\mathbf{b}$ low erosion power 


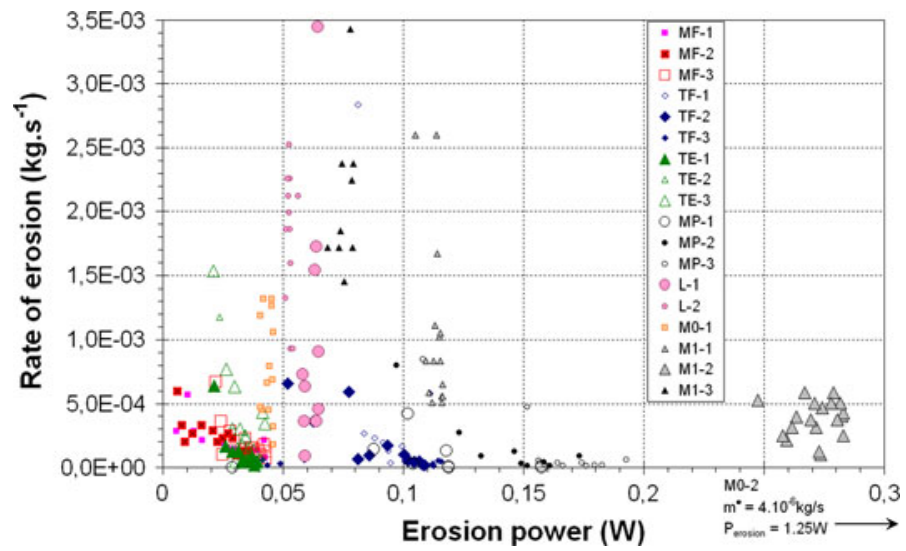

Fig. 5 Rate of erosion versus erosion power determined by JET

$$
I_{\alpha}=-\log \left(\frac{m_{\mathrm{dry}}}{E_{\text {erosion }}}\right)
$$
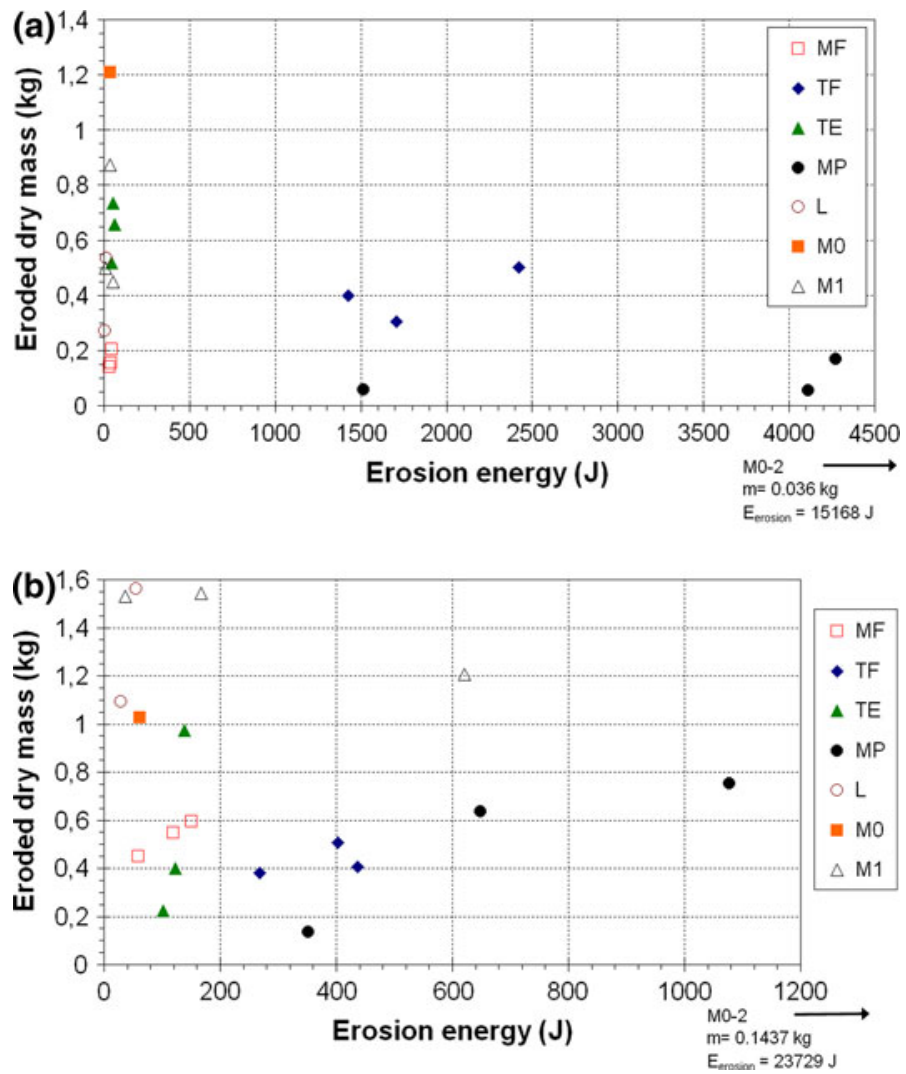

Fig. 6 Eroded dry mass versus erosion energy determined by a HET and b JET 


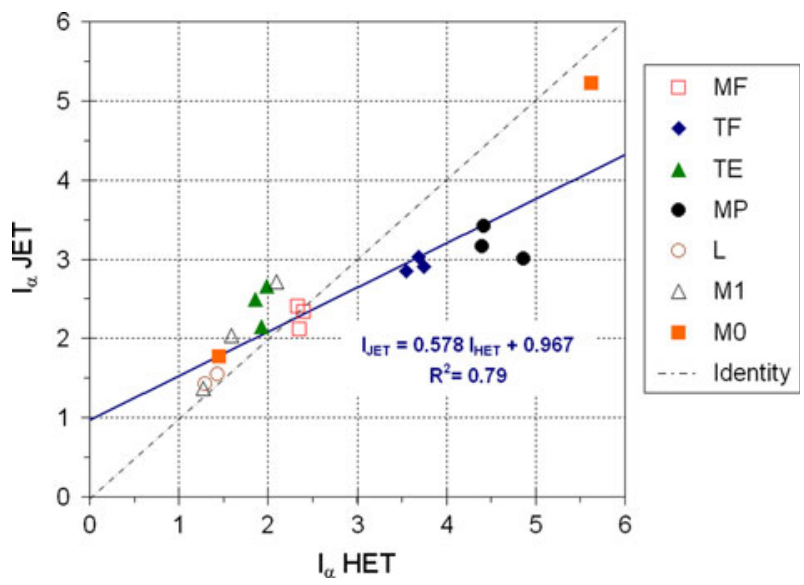

Fig. 7 Erosion resistance index determined by JET versus erosion resistance index determined by HET

As shown in the Fig. 7, obtained values of $I_{\alpha}$ index with JET $\left(I_{\alpha \mathrm{JET}}\right)$ are related to values obtained with HET $\left(I_{\alpha \mathrm{HET}}\right)$ by:

$$
I_{\alpha \mathrm{JET}}=0.578 I_{\alpha \mathrm{HET}}+0.967 \quad\left(R^{2}=0.79 ; N=19\right)
$$

The comparison of the position of each soil on $I_{\alpha}$ chart shows that the relative erodibility classification of the seven tested soils is identical for both devices. From the most erodible to the most resistant, with the HET and JET, the obtained classification is: L, M1, TE, MF, TF and MP. A first specimen of M0 soil is erodible, whereas a second is highly resistant.

In comparison with values determined by HET, the values of $I_{\alpha}$ appear underestimated by JET for resistant soils and slightly overestimated for erodible soils.

In contrast to the precedent models based on stress, energy model leads to a same classification of soil erodibility for JET and HET. This single classification permits to choose the more suitable one between HET and JET device. For instance, to choose a JET can simplify studies on low-plasticity soils or on saturated soils. Another advantage of the JET is that it can be used on site and measure the intact resistance. For a use in situ, the eroded wet mass can be determined from soil density and eroded soil volume measurements. The volume of eroded soil can be determined with several pin profiler measurements (the principle of this device is described in A.S.T.M. Standard D5852).

\section{Conclusions}

The HET and the JET are frequently used to characterize the sensitivity of a soil to a hydraulic stress. Analysis of these test results by existing methods leads to values of erosion rate coefficient and critical shear stress which are specific to the used device. A new analysis is based on the erosion power and on the rate of eroded mass. By integrating over the time, the eroded mass measured is correlated to the fluid energy expended. A new erosion resistance index is proposed, and the obtained values are compared between the two apparatuses. By using the energy analysis, an identical erodibility classification of the seven tested soils can be obtained with both devices. 
Acknowledgments The authors would like to acknowledge Greg Hanson of the USDA-HERU Stillwater, $\mathrm{OK}$, for his authorization to reproduce the jet apparatus and for advice on its use. USBR-Denver (Tony Wahl), ERDC-Vicksburg (Johannes Wibowo) and EDF (Jean-Robert Courivaud) are acknowledged for the funding of a part of the work and for their advice.

\section{References}

A.S.T.M. Geotechnical engineering standards (2000) Standard test method for erodibility determination of soil in the field or in the laboratory by the jet index method. D5852. ASTM International, West Conshohocken, PA, United States

Beltaos S, Rajaratnam N (1974) Impinging circular turbulent jets. J. Hydraul Div ASCE 100(HY10): 1313-1328

Blaisdell FW, Anderson CL (1981) Ultimate dimension of local scour. J Hydraul Div ASCE 107(HY3): 327-337

Bonelli S, Brivois O (2008) The scaling law in the hole erosion test with a constant pressure drop. Int J Numer Anal Methods Geomech 32(13):1573-1595

Bureau of Reclamations: Material Engineering Branch, Research and laboratory services division (1990) Earth manual-part II: Water resources technical publication, 3rd edn. Bureau of Reclamation Denver, Department of Interior, Washington DC

Dunn IS (1959) Tractive resistance of cohesive channels. J Soil Mech Found Div ASCE 85(SM3):1-24

Hanson GJ, Cook KR (2004) Apparatus, test procedures, and analytical methods to measure soil erodibility in situ. Appl Eng Agric Am Soc Agric Eng (ASAE) 20(4):455-462

Hanson GJ, Simon A (2001) Erodibility of cohesive streambeds in the loess area of the midwestern USA. Hydrol Process 15(1):23-38

Hanson G, Robinson KM, Temple DM (1990) Pressure and stress distributions due to a submerged impinging jet. In: Proceeding national conference hydraulic engineering, ASCE., San Diego, CA, pp 525-530

Idel'Cik, IE, Meury M (Trans) (1986) Memento des pertes de charge: coefficients de pertes de charge singulières et des pertes de charge par frottement. Collection de la Direction des Etudes et Recherches d'Electricité de France, Eyrolles, Paris France

Regazzoni PL (2009) Confrontation et analyse d'érodimètres et caractérisation de la sensibilité à l'érosion d'interface. PhD thesis, Université de Nantes, France

Wahl T, Regazzoni PL, Erdogan Z (2008) Determining erosion indices of cohesive soils with the Hole Erosion Test and the Jet Erosion Test. Dam Safety office report DSO-08-05, US Bureau of Reclamation-Denver

Wan CF, Fell R (2004) Investigation of rate of erosion of soils in embankment dams. J Geotech Geoenviron Eng 130(4):373-380

White FM (1999) Fluid mechanics, 4th edn. WCB McGraw-Hill, Boston 